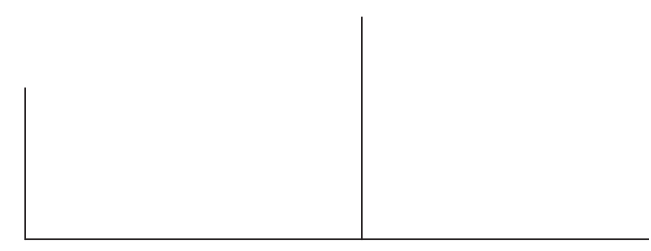

\title{
Repetir a palavra alheia, ou De como refletir sobre esse sintoma na companhia da psicanálise
}

\author{
Ruth Palladino
}

Repetir a palavra alheia, ao lado do silêncio, é um dos sintomas mais freqüentes nas patologias da linguagem. Tradicionalmente denominada ecolalia, esta repetição é entendida como produção não intencional, inconsciente, que não é representativa de conhecimento objetivo da realidade. É apenas eco: uma fala que para nada serve. Desde uma perspectiva lingüística mais moderna, que toma a palavra como algo da instância discursiva (que aposta na polissemia da palavra e na heterogeneidade do sujeito), a repetição pode ter uma outra interpretação. Do interior do conceito de enunciação advém a idéia de incompletude do sujeito e da linguagem, determinando para a linguagem uma gênese que nada mais é senão o brotamento de um funcionamento do tipo simbólico em que a repetição fica como um acontecimento fundante. Resgatada por esta lingüística, a repetição permanece, entretanto, exigindo análise. A patologia de linguagem mostra uma repetição cujo destino é diferente: longe de notar uma ocorrência fundante, ela revela seu perverso poder, já que tira da palavra sua possibilidade em advir um dizer. Esta ocorrência passa a ter outra natureza e sobre isto a psicanálise tem muito a dizer.

A repetição, ocorrência fundante, perde seu caráter original e significa o patológico. Fica exorbitado o lado conservador das pulsões, esfumaçando a heterogeneidade do sujeito, interditando qualquer anarquia no funcionamento pulsional, fonte da diferença necessária. A palavra é uma invenção: pelo seu caráter polissêmico ela é sempre uma solução inédita. Quando a criança repete a palavra do outro é como se ela a fizesse sua, instaurando a diferença. Na patologia, diversamente, a criança não faz sua a palavra alheia e, assim, deixa de ser uma invenção porque fica destituída da possibilidade de instaurar o novo. Acaba a dialética condicional entre invenção/repetição, daí a morte da palavra. 


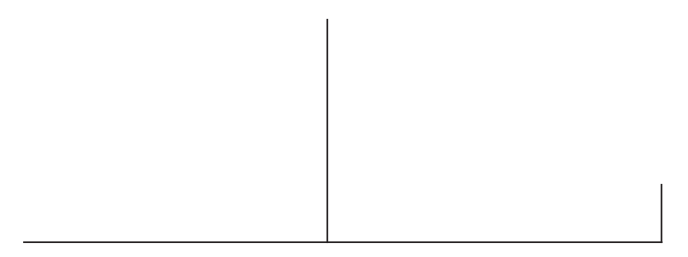

\section{I - O campo fonoaudiológico e a questão do sintoma: um encontro mal resolvido}

Os fonoaudiólogos que trabalham principalmente com crianças com atraso de linguagem se deparam, com freqüência, com casos de pacientes que ora estão silentes, ora não fazem outra coisa senão repetir a fala alheia. Sem tentar desproblematizar a questão do silêncio, seria importante tomar esta repetição que se apresenta e insiste porque, me parece, merece discussão.

$\mathrm{Na}$ análise fonoaudiológica tradicional, a repetição, denominada ecolalia, é considerada um uso da palavra dito improdutivo, já que há na boca da criança apenas uma cópia da fala alheia e, como tal, é produção desprovida de intenção, que demonstra não representar qualquer conhecimento objetivo da realidade. $\mathrm{O}$ som que a criança produz não passa de um eco: um uso alea-tório da palavra que para nada serve. Não é linguagem, já que só o são as produções inteligíveis, de reconhecida autoria, para representação de conhecimento, resultante de um ato comunicativo intencional e, portanto, feitas de modo consciente.

Se a repetição é marginal, o silêncio não o é menos, dado que, de uma outra forma, ele também mostra o "fora" da linguagem e tanto um quanto o outro acontecimento, em última instância, acabam tendo o mesmo destino aos olhos dos fonoaudiólogos: são desprestigiados. Em outros termos, para eles, no material que pode ser considerado de valor para a reflexão clínica, o silêncio e a repetição aí não comparecem. Apenas servem para publicar inequivocamente a existência de um problema. Tal proposição é, no mínimo, interessante porque justamente ao critério do olhar fonoaudiológico (olhar de um campo que toma a palavra como matéria-prima) a fala do paciente é desconsiderada. Além de interessante, parece mesmo paradoxal e, portanto, é preciso supor que a repetição deve, sim, ser alçada à condição de sintoma e, como tal, convoca reflexão. Para tanto, parece não haver saída 
senão ir buscar uma outra hipótese no interior da qual se possa, talvez, contemplar este acontecimento de forma mais apropriada. Se não mais própria, menos insólita.

\section{II - A repetição sob o olhar circunspecto da Fonoaudiologia: a impertinência de uma necessidade}

O conceito de ecolalia surge no bojo de uma concepção que toma a palavra como recurso (inegavelmente) engenhoso de intercâmbio - do conhecimento e das emoções - entre as pessoas. Ou seja, palavra é artefato. Se assim for, é produto de convenção e, para tanto, deve conter, segundo Laudesman (apud Orlandi, 1992, p. 99) "a regularidade, o aspecto teleológico, o caráter arbitrário e o fato de não ser acidental".

Desde esta concepção, a comunicação é natural ao homem e, a palavra, é adquirida a posteriori, por aprendizagem, dado que ela é um artefato e, portanto, deve ser adquirido. Na aprendizagem estão implicados um organismo (na função de "pedagogo") competente e estimulante e, sua contraparte, um outro organismo (na função de "aprendiz") bem posto e estimulado o que significa, em última instância, que está postulado um período de preparação para seu advento, anterior à palavra. E, portanto, há uma teleologia nesta concepção porque está previsto um caminho do nada para um absoluto, representado pela figura do "ser falante". Se a linguagem é posterior, ela, é claro, não comparece na constituição dos sentidos. Insurge após, para operar seu intercâmbio e, não se pode negar, expandir as redes de significação sem, contudo, alcançar jamais o estatuto de elemento fundador. Porque artefato comunicativo, a questão da estrutura formal se impõe: a palavra deve sempre se apresentar na sua melhor plástica para exercer dignamente sua função. E dignidade aqui se refere principalmente à preservação do sentido intercambiado e, com isso, deve haver forma perfeita e univocidade, ou seja, fixidez na relação entre a forma e o sentido: uma palavra perfeitamente formatada para um sentido absolutamente transparente. Fica, assim, absolutizada a "função da informação, imobilizando a linguagem fora de sua multiplicidade" (Orlandi, p. 120). Assim, toda palavra que não tiver tal perfil e/ou não servir para tal função não é "digna". Como as repetições.

As hipóteses fundamentais contidas no conceito de comunicação (naturalidade da comunicação e aprendizagem da palavra, a constituição dos sentidos e o caráter unívoco da palavra e, por fim, a convocação de ordens heterogêneas para a compreensão dos processos da linguagem) merecem ser polemizadas verticalmente, pois não são nem muito interessantes, nem profícuas à causa fonoaudiológica. 


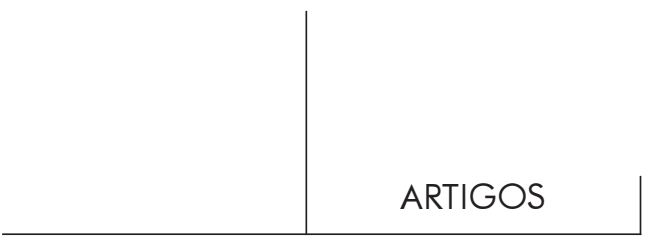

Em primeiro lugar, vale pensar na questão da aprendizagem. Se a palavra surge por aprendizagem, essa sua gênese vai determinar para sempre o impossível de uma instância clínica, terapêutica. A situação de aprender implica um "pedagogo" que, por já deter todo o sistema de artefatos, cuida para apresentálo gradativamente ao "aprendiz", garantindo um uso plenamente apropriado tanto no que se refere à forma quanto à garantia da veiculação de um sentido certo. É o "pedagogo", enfim, que controla o andamento do processo de formação do falante. Ensino e controle: tudo isto está longe da noção de heurística, tão cara ao conceito de terapeuta porque constitutiva desta posição. É por isto que não há como evitar e fica fácil entender o viés pedagógico que dá o tom à prática fonoaudiológica tradicional.

Em seguida, são importantes algumas considerações acerca do problema de a linguagem ser tomada como um epifenômeno. A idéia de um período anterior à palavra traz consigo, necessariamente, uma outra. $\mathrm{O}$ organismo se prepara para aprendizagem da palavra: condições somáticas, psíquicas e sociais devem ser garantidas para que o organismo seja transformado em falante e possa trabalhar com competência com os tais artefatos comunicativos envolvidos. A palavra fica, pois, como produto resultante da participação de estruturas e funções no organismo e, em conseqüência, para a compreensão do advento da linguagem, seu desenvolvimento e sua patologia inclusive, instâncias outras (estranhas a ela quanto à sua natureza) devem ser evocadas. A palavra é causada por outra ordem; é epifenômeno e isso quer dizer que na desordem da palavra o que ocorreria é que se "manifestaria em um registro aquilo que é alteração do outro". (Bogochvol, 1997)

Supor a não autonomia da linguagem relativamente às outras ordens pulveriza o campo fonoaudiológico à medida que, para o processo diagnóstico e para as proposições terapêuticas, elementos destas ordens diversas são os que têm participação determinante. À Fonoaudiologia pouco resta sobre o que refletir; ela existe na condição de "prescrição". É interessante verificar que os acontecimentos não são tomados como uma "questão da palavra", mas, sim, como uma questão somática, psíquica e/ou social e o sofrimento da palavra fica como forte prova de algum problema nestas ordens. É como se o sofrimento da palavra não merecesse uma reflexão específica ainda que ela também seja alguma coisa do universo somático, psíquico e social. Sem reflexão específica, ou seja, sem o compromisso teórico, ao fonoaudiólogo é entregue apenas a responsabilidade de executar um adicional ou curativo ou corretivo. Apenas "adicional", porque a ação que tem propriedade e efeito está projetada ou pelo médico, ou pelo psicólogo, pelo psiquiatra ou, então, pela professora. São eles que criam "exercícios" (os "adicionais") reforçadores aplicados pela família e pelo fonoaudiólogo. 


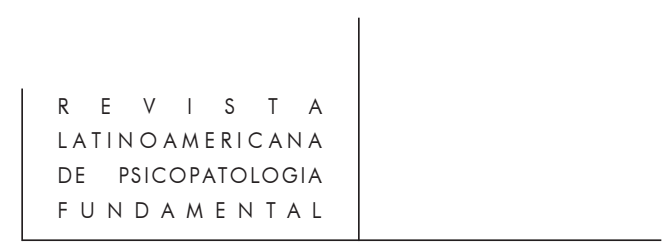

Finalmente, é importante discutir a noção de sentido como externo à de linguagem. A questão da posterioridade da linguagem cria um outro problema: a existência de algo construído (ou, pelo menos, inicialmente construído) e que há de ser representado posteriormente pela palavra nas performances comunicativas. Assim fica explicada a razão de a palavra advir e também fica óbvia sua ausência no processo de construção deste "algo anterior" que parece não ser outra coisa senão o sentido. Aqui fica subtraída ao campo fonoaudiológico uma lida importante que é a questão do sentido e, com isto, será preciso retirar da alçada deste campo casos que não sejam disfonias e distúrbios articulatórios de natureza periférica. Em tudo o que resta, sem considerar o sentido, nada há da ordem do possível.

Este problema do sentido é mais extenso do que parece. A idéia de comunicação traz em si uma outra: a de univocidade. A polissemia como criando a palavra está descartada: não há sentido que se movimente, que se monte e desmonte, nunca há um possível a mais, a palavra nunca deve ter uma outra em sua dobra. Mais uma vez a questão fonoaudiológica fica minimizada. Por um lado porque não é possível supor uma situação terapêutica no interior da idéia de univocidade que é a exclusão dos sentidos, já que, se assim o for, alguém há de receber a incumbência de operar a exclusão e quem o faz, porque o faz, determina o rumo dos acontecimentos. Terapeuta? Ora, terapeuta não é aquele que "se inclina sobre o paciente e escuta essa voz única se dispondo a ter, assim, junto com o paciente, uma experiência que pertence aos dois" (Berlinck, 1998, p. 55)? Por outro lado, fica difícil a reflexão alcançar certos acontecimentos que ao fonoaudiólogo se apresentam com insistência e evitar pensar em considerálos "uso impróprio dos artefatos comunicativos". Aqui vale trazer um caso apresentado por uma fonoaudióloga durante nossas reuniões para estudo de caso na Universidade, porque o que ali foi exposto pode ser considerado emblemático da questão apresentada. A paciente, uma menina de 9 anos, sem graves danos, construía, a cada sessão, um diálogo muito curioso com a terapeuta. Cito um trecho mínimo de um deles, mas que pode, sem problema algum, representar muito bem o comentado: conversando sobre a família da paciente, a terapeuta pergunta sobre a profissão do pai: "E o seu pai, o que ele faz?" Ao que a paciente responde: "Faz de propósito." Para os fonoaudiólogos, o que fazer com isto à luz de uma concepção que toma a palavra como artifício comunicativo? A eles nada resta senão pensar que a menina "errou". E a idéia de "erro" está presa à de "má escolha". Se o exemplo vale ser citado, acho igualmente válido trazer aqui uma consideração de Berlinck (1998) sobre a questão do pathos: "quando pathos acontece, algo da ordem do excesso, da desmesura se põe em marcha sem que o eu possa se assenhorar desse acontecimento, a não ser como paciente, como ator." (p. 53). Considerações como essa trazem algum alento para os 


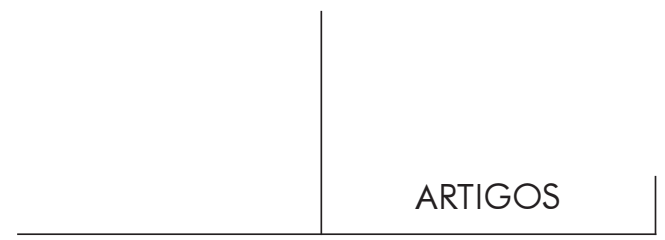

fonoaudiólogos: à luz de outros pensamentos, talvez haja mesmo um outro possível.

O campo fonoaudiológico deverá poder tocar naquilo que até hoje lhe é proibido: a questão do sujeito e do sentido porque, ao que parece, é a maneira de ser erigida uma reflexão extensa e complexa, condição única para um campo menos pobre e menos iletrado, com a promessa de construção de uma teoria que, entre outros compromissos, dê sustentação a uma práxis terapêutica. Entretanto, alguns "exorcismos" ainda devem ser operados para que a reflexão possa se instaurar.

Uma concepção de linguagem enquanto recurso comunicativo, de troca, comporta necessariamente uma teleologia, já que há um absoluto posto no horizonte. Quer dizer, postula-se a existência de um organismo primitivo, naturalmente comunicativo, que se torna um falante, indivíduo competente na lida com um sistema de artefatos comunicativos discriminadamente sofisticado entre todos os existentes. Há um amadurecimento do organismo e um amadurecimento da palavra: funções cada vez mais complexas estão na base de conjuntos cada vez mais extensos de artefatos e isto significa que ambos, organismo e linguagem, passam por "evolução". É o que Ogden (apud Figueiredo, 1997) comenta (na sua discussão sobre subjetivação) das visões evolutivas: "o passado da experiência é conservado numa forma superior" (p. 165). O que desvia desta rota evolutiva é "doença". Mas a patologia mostra que o sentido não é "exatamente evolutivo"; a patologia problematiza a teleologia onde a heterogeneidade/a diversidade são indícios de "imaturidade", são passos para o advento do absoluto. Seria interessante pensar de maneira modificada: em vez da homogeneidade, do repouso da palavra, representar o alcance do absoluto (a normalidade), deveria, diferentemente, apontar para a doença e, portanto, ao sujeito iria restar, por solidariedade a essa postulação, uma constituição, por essência, de movimento e heterogeneidade eternos. Mais uma vez Ogden, ao discutir a formação do psiquismo, afirma que "[..] se pode ver instaurada no psiquismo uma dialética de 'ausência e presença' em que o pólo 'presente' sempre repõe os 'ausentes' e a eles remete, o que deflagra uma incessante temporalização subjetiva”. (p. 165)

Resta, ainda, um "senão": o problema da natureza da palavra. Para que o campo fonoaudiológico possa refletir mais acertadamente é preciso que fique negada a existência de um sentido unívoco, pleno. É preciso postular um processo de significação que se faz, desfaz e se refaz incessantemente e, portanto, o sentido não é nem homogêneo nem se cristaliza plenamente. Para além disto, a palavra precisa ser incorporada neste processo. Se a ela não for dada qualquer forma de participação no processo de significação, ela não terá outro destino senão o de ser artefato, instrumento de comunicação. E aqui, mais uma diferença 


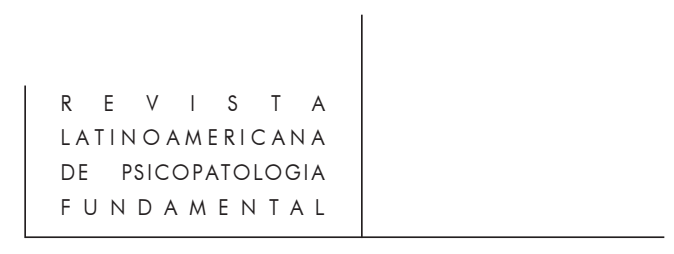

pode ser inscrita: a "humanização" está ligada essencialmente à comunicação (o que não significa negar a comunicação como um grande recurso que garante a existência das pessoas)? Ou está ligada ao simbólico? A "humanidade" não seria a injunção ao sentido, destino irrecusável de todos os homens? Bogochvol (1997, pp. 18-19) traz considerações nesta linha. Ele aponta: "[..] se na perspectiva darwinista o homem está próximo de seus ancestrais símios e se partilha com os chimpanzés $99 \%$ de sua carga genética, este $1 \%$ de genes que os diferenciam, esta pequena diferença quantitativa no plano biológico pode se traduzir em mudanças qualitativas fundamentais e é nesta diferença que encontramos as condições biológicas de sua homonização. Este processo implica, necessariamente, no encontro de um corpo biológico, genético, de um organismo com um universo estritamente simbólico".

Seria impertinente pensar que o sujeito fala porque a palavra tem participação na fundação dos sentidos? Ignorando uma possível impertinência, me parece quase inadiável trazer esta suposição para o raciocínio do campo fonoaudiológico.

\section{III - A repetição no espelho da lingüística: a permanência de uma angústia}

Há certos estudos contemporâneos da linguagem que podem ser espaços férteis e instigantes para a discussão fonoaudiológica. A análise de discurso (de linhagem francesa) e a aquisição de linguagem (de linhagem interacionista social) trazem idéias importantes para a questão que se quer aqui tratar. Os estudos do discurso são fonte importante para a discussão acerca da polissemia da linguagem e da heterogeneidade do sujeito. Os estudos de aquisição, por sua vez, proporcionam condições para se pensar a gênese da linguagem (na abolição de uma teleologia) e a questão da repetição, tomada como processo revelador da linguagem.

Orlandi (1988), numa visão discursiva, aponta dois pontos principais. Um, se relaciona à natureza polissêmica da palavra. Aqui, destituída de seu caráter unívoco, a palavra ganha dobras, ou seja, o sentido por ela presentificado põe em silêncio outros, ali mesmo. E, nesta medida, na palavra há sempre um outro possível. $\mathrm{O}$ outro ponto pode ser remetido à natureza heterogênea do sujeito. $\mathrm{A}$ heterogeneidade é anunciada no conceito de polifonia. O sujeito existe em diferentes posições, ele é dividido na enunciação e só aí é que se dá a constituição dos sentidos, ou seja, na instância do discurso. O falante é só material empírico: nesta instância já há a constituição de um sentido entre os infinitamente possíveis (o que gera a impressão da autonomia/autoria do sujeito) e a construção de um 


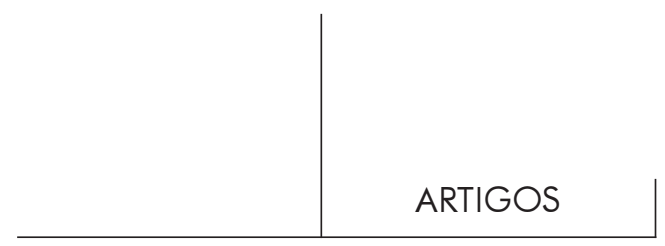

texto entre as possibilidades que a língua sugere (o que gera a impressão da unidade do dizer). Daí a "transparência e objetividade" que caracterizam a palavra do falante.

Numa perspectiva interacionista da aquisição da linguagem, Lemos (apud Pereira de Castro, no prelo) propõe o processo de aquisição de linguagem como uma diferença constante. A autora postula os processos metafóricos e metonímicos como os grandes mecanismos de mudança e assevera que qualquer estabilização aparente não pode ser tomada como "um ponto final na atuação desses processos, já que uma certa homogeneidade na fala dos adultos não os homogeneíza enquanto falantes, não elimina a singularidade e a diferença, nem detém a mudança lingüística". O que está aqui é uma proposta de constância dos processos de aquisição, cujo efeito contém sempre a diferença. Além da rejeição de uma teleologia, tal perspectiva também apresenta crença na idéia de polissemia da linguagem e na da heterogeneidade do sujeito. Pereira de Castro, fazendo considerações acerca da tensão entre reconhecimento e estranhamento nas relações da criança com a língua, aponta que quando a criança vai da posição de interpretada pelo outro à interpretada pela língua, para assumir a posição que marca o funcionamento do sujeito no simbólico, isto é, sua divisão entre ser autor de seu enunciado - intérprete de sua própria fala (e da fala do outro) e ser interpretado/falado pela língua. Divisão que não está mais na superfície da fala, mas que deixa ver sempre que um ponto de subjetivação irrompe na cadeia, sempre que a homogeneidade é suspensa, mostrando as relações entre as cadeias manifestas e as cadeias latentes."

É no interior destas idéias que a perspectiva interacionista da aquisição da linguagem propõe algo de muito interessante para a questão das repetições. Lemos (1985) toma a especularidade como movimento fundante do sujeito: ao repetir a fala alheia, a criança assume uma posição discursiva e, assim, movimenta-se na estrutura da linguagem, denotando um funcionamento que é de natureza simbólica. Diferentemente de ser "marginal" (acontecimento da pré-linguagem, performances preparatórias e, assim, ainda não linguagem) a repetição recebe o estatuto de movimento determinante e já é linguagem desde sempre. Outro importante aspecto que o conceito de especularidade traz se refere à idéia aí contida de que a repetição implica em diferença: a incorporação da fala do outro denota identificação e a assunção de uma posição discursiva denota que há identificação na alteridade. Com isto, tal conceito se discrimina de forma incorrigível da noção de imitação.

A proximidade conceitual entre estes estudos da linguagem permite construir um diálogo bastante importante entre o campo fonoaudiológico e a lingüística. Mas, não se pode negar, a ocorrência clínica insiste em desnudar a falta: a ocorrência sempre cria um "senão" e demanda outra rota. Quero dizer que o 


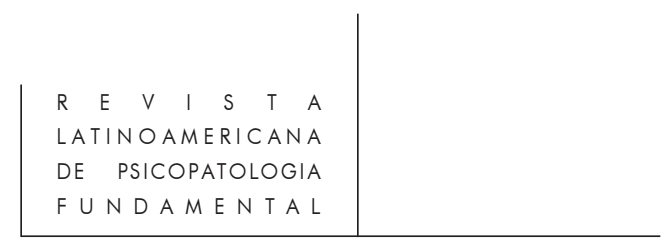

dado clínico, mesmo que refletido no interior da lingüística, permanece interrogando o fonoaudiólogo.

\section{IV - A repetição no espelho da psicanálise: promessas de uma conversa séria}

As crianças com atraso de linguagem, como já apontei, não ficam só em silêncio, elas também falam. E quando o fazem, repetem a fala alheia. Entretanto, neste caso, fica difícil perceber a repetição como "movimento determinante", "constitutivo": parece que ao ser repetida, a fala alheia fica despida da possibilidade de significar, imóvel para a errância dos sentidos. A essa fala fica subtraído o estatuto de "dizer". Assim como entra pela boca da criança, daí sai, escorregando, se perdendo. Em outros termos, ao repetir a fala do outro, a criança daí extrai qualquer significação possível e "joga fora as palavras", joga para fora e como um nada, produzindo um efeito devastador no outro, que tende ao silêncio. As mães destas crianças trazem nas entrevistas mostras de um profundo desalento e alegam desistir de falar com os filhos porque eles "destroem" tudo o que elas tentam dizer. Segundo as mães, as crianças não "conversam", só ficam "papagueando". Isto é interessante e, talvez, aqui caiba uma paráfrase: as crianças não funcionam como "gente", mas como "bicho", como "papagaio"; gente faz outra coisa com as palavras. E os terapeutas não ficam atrás. Uma grande dificuldade na terapia destas crianças é suportar a repetição e não deixar o silêncio e a negação tomarem conta de tudo. O que é que acontece aí? Talvez de um outro lugar, será possível e fecundo tomar as repetições para decifração, sem esquecer que, para a causa fonoaudiológica, este "outro lugar" deve implicar a possibilidade de a palavra trazer consigo a questão do sentido e do sujeito.

A leitura que posso fazer de alguns escritos psicanalíticos me conduz à suposição de que a psicanálise pode ser este "outro lugar" porque parece trazer a possibilidade de tratar as questões tão caras à Fonoaudiologia. O texto de Berlinck (1998) que toca na hipótese freudiana das bases filogenéticas na explicação da formação do psiquismo e o de Garcia-Roza (1991) sobre a parte inicial da psicanálise freudiana, abrem um caminho bastante iluminado que, a meu ver, se trilhado, poderá levar a lugares interessantes de discussão.

No citado texto de Berlinck, é possível depreender que o conflito é substrato do psiquismo, ou seja, o ato psíquico é sempre uma solução criativa para as perturbações. Se criação, é da ordem pulsional exatamente porque o caráter errante (transferencial) da pulsão é o que permite o deslocamento da libido para objetos outros que respondem criativamente ao conflito. Mas, por ser errante e 


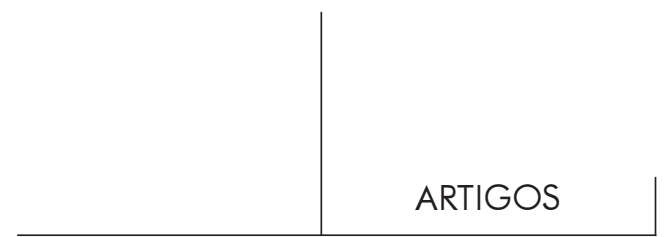

não colante como o instinto, a pulsão desloca objetos, ou melhor, "se desloca investindo novos objetos com propriedades e significados de outros objetos" (p. 14). Parafraseando, uma coisa pode vir a ser outra e vice-versa e outra ainda e assim por diante, infinitamente: toda criação é pulsão e, por conseguinte, é algo da instância da significação. Ora, se a palavra é um ato de criação (“...complexo e ardiloso movimento feito pelo macho de constituição do símbolo que termina na palavra" [p. 18]), é da ordem pulsional e, assim, ela é também da ordem do sentido.

Se não posso considerar a palavra como fundante do sentido, presente em todo ato criador, já que há soluções que ficam "onto e filogeneticamente fora do âmbito da palavra" (p. 99), posso, talvez, considerar o inverso, ou seja, o sentido como fundante da palavra. Para os problemas fonoaudiológicos isto basta e é precioso: a palavra não tem existência independente e posterior ao sentido.

Berlinck (1998), ao discorrer sobre o dito "mito contemporâneo", mostra que, de fato, a palavra é gerada no ventre da significação: ... a introdução do sucedâneo produz um duplo deslocamento: por um lado, a criança sai do esquema de satisfação da necessidade e é introduzida no esquema do prazer e, por outro, é remetida ao mundo de deslocamentos simbólicos que a lançam a caminho da palavra." (p. 19). E continua: "O prazer contém um engano, uma mentira que se origina na falência do esquema de satisfação da necessidade. Esta fundamental mentira é a base para o campo das equivalências simbólicas e para a polissemia que impregna as palavras" (pp.19-20). E o que é a mentira senão uma questão estrita de semântica? Só quando no símbolo é inscrita a mentira, surge a palavra: solução criativa encontrada pelo homem frente à nova ameaça de sobrevivência da espécie: “... o macho é levado a buscar e encontrar um sistema que o possibilite reconhecer o período de fertilidade da fêmea. Nasce desta forma o símbolo que só adquire estatuto de palavra quando se encontra com a mentira própria da fêmea solicitada pelo prazer.” (p. 17)

Nascida na significação, a palavra vai receber uma função especial: ao ser presentificada na voz, ela se torna, inclusive, lugar da comunicação. Mais uma vez, Berlinck não se põe longe disto ao colocar que "a este trabalho inteligente de criação de símbolos que resulta na palavra adiciona-se, também, um longo e persistente controle sobre as cordas vocais que implica num investimento libidinal que, por anfimixia, vai resultar na voz humana". (p. 18)

É interessante, para a questão da natureza e da função da palavra, o texto de Garcia-Roza (1991) que traz um comentário sobre a diferença postulada por Freud, no "Tratado das afasias", entre o que está posto como a "ordem do signo" e a "ordem do símbolo". Segundo ele, a linguagem está na sua função sígnica quando "representa alguma coisa para alguém" (p. 63); é a relação representaçãoobjeto com a coisa. A função simbólica, diferentemente, se dá na instância da 


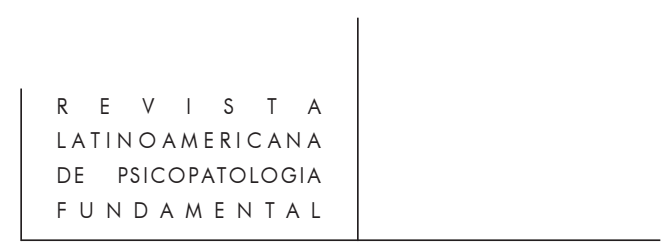

relação entre as representações (representação-coisa e representação-palavra) e é pré-condição para o estabelecimento do signo.

Dito de outra forma, antes de comunicar, a palavra significa. São sintomáticas as considerações do autor sobre a agnosia, desde uma análise freudiana: "Na agnosia, o que está perturbado é a relação entre representaçãoobjeto e a coisa, sendo que a relação entre as representações permanece intacta, o que corresponde a dizer que o aparelho de linguagem não é atingido" (p. 62). Não há distúrbio de linguagem na agnosia, o que permite a conclusão da linguagem ser uma instância que sempre implica a relação entre as representações; é possível dizer, implica o sentido.

$\mathrm{Na}$ leitura dos textos, pode-se perceber que nas discussões sobre a clínica psicanalítica, a palavra comparece na sua função comunicativa que é maximizada para efeito de argumentação. Berlinck (1998) retoma Fédida para considerar que "a interlocução que se estabelece na clínica psicanalítica é só aparentemente da ordem da palavra, mas o que verdadeiramente se engaja é da ordem da transferência” (p. 22). Se a pulsão é transferencial - errante -, o que não é outra coisa senão a possibilidade de deslocamento da libido para outros objetos, ela é o substrato da criação e, portanto, da instância do sentido. Com isto, parece que na clínica psicanalítica o que verdadeiramente se engaja é da ordem do sentido. Mas parece que da palavra - é muito lembrada nas discussões acerca da clínica psicanalítica - a possibilidade de ela ser "veículo por excelência das transferências" (p. 22). Ou ela é uma possibilidade preciosa do deslocamento da pulsão? A revelação, a presentificação de um sentido? Mesmo quando se afirma que a psicanálise é uma talking cure, é possível pensar que também aí a palavra não surge na sua função comunicativa: ao falar, o paciente revela um sentido, é uma criação. Suponho que a fala do paciente não seja a publicação de uma criação. O público, quem é? O terapeuta? A fala do paciente não é uma criação? Até na reflexão sobre os sintomas este privilégio é notado. Berlinck (1998) comenta, numa certa passagem, que "a prática clínica nos leva a reconhecer, então, no ato falho, uma perturbação no controle da voz..." (p. 18). Será que o ato falho não mostra exatamente que o sujeito não controla seu dizer? Parece que não é a voz, mas a palavra, que foi traída. Ou a palavra traiu o sujeito? Garcia-Roza (1991) lembra que Freud, para estudar as afasias, teve cuidado especial com um certo tipo de acontecimento, as parafasias, que é a troca de um termo por outro. Isto mostra o deslizamento nas relações entre representações, provocado pela "ação de afetos intensos sobre a linguagem... sem que para isto tenha ocorrido a vontade consciente do sujeito" (p. 67): eis a primeira insinuação da instância do inconsciente. As palavras e os sentidos deslizam, deslocam. A voz gera matéria empírica para uma possibilidade que se presentificou provisoriamente. Mas esta é uma discussão privada, ela não concerne aos fonoaudiólogos. O que eles disto 


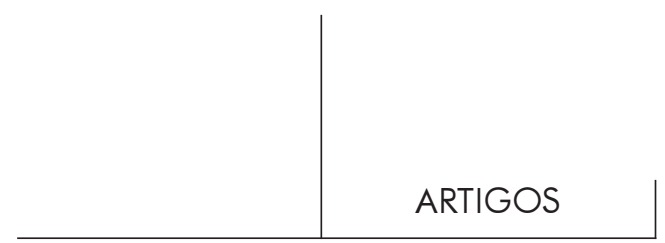

tudo podem depurar é que a psicanálise é um lugar muito bom para erigir uma reflexão porque, de qualquer forma, põe o sentido na alma da palavra e essa é uma condição vital para o campo fonoaudiológico.

A psicanálise é também lugar profícuo para a reflexão sobre a questão da repetição, uma noção que comparece em diferentes núcleos deste campo. No que tange à questão clínica, a idéia de repetição é evocada como inerente ao conceito de sintoma. A repetição é, pois, a insistência do conflito em resolver-se e, para tanto, ele é reproduzido de modo disfarçado sucessivas vezes. O que permanece incompreendido, gera conflito e retorna, numa solução possível para isto.

A repetição também comparece nas hipóteses que o campo psicanalítico levanta acerca da constituição e funcionamento do psiquismo. Ela está inserida no campo das pulsões e desempenha papel importante no jogo entre o prazer e a realidade, se ligando ao caráter conservador das pulsões. Energia intensa cuja pressão é irreprimível, as pulsões são indeterminadas, ou seja, podem ter diferentes objetos e metas. A esta pressão intensa e a esta indeterminação, a repetição se apresenta como modo de "retorno ao repouso absoluto" (Laplanche e Pontalis, 1992, p. 412). O funcionamento do psiquismo se dá numa dialética entre a invenção e a repetição, sendo cada ato psíquico ligado a um dos traços fundamentais da pulsão: ou o mais desagregador ou o mais conservador. A repetição é uma solução para a indeterminação, porém a pulsão não resolvida é conflito, daí a repetição advir sintoma.

Parece viável pensar a repetição da fala alheia nestes mesmos termos. A repetição, movimento fundador do funcionamento da linguagem, lugar de identificação, que por conter a diferença é instância da alteridade constitutiva do sujeito, perde seu caráter originário e significa o patológico. A repetição parece exorbitar o lado conservador das pulsões, esfumaçando a heterogeneidade do sujeito, represando a energia, ou melhor, interditando qualquer anarquia no funcionamento pulsional, fonte da diferença necessária do sempre inédito. Se a repetição é, nestes casos, a reedição do mesmo, ela inviabiliza a alteridade, não pode ser alçada à condição de lugar de identificação.

A psicanálise trata da identificação em duas vertentes de possibilidade. A primeira, seria considerar a identificação como um processo de reconhecer no externo a semelhança. Para as questões de linguagem (na ótica aqui tratada), esta possibilidade é complicada porque para a criança reconhecer na fala alheia semelhança, é necessário que ela já seja capaz de tomar uma posição minimamente analítica diante da linguagem. Pereira de Castro aborda em seu trabalho exatamente o problema da tensão entre reconhecimento e estranhamento nas relações da criança com a língua e mostra, com clareza, a dialética que está envolvida neste processo que é eterno. Mostra que não há um momento de prontidão plena para a análise. 


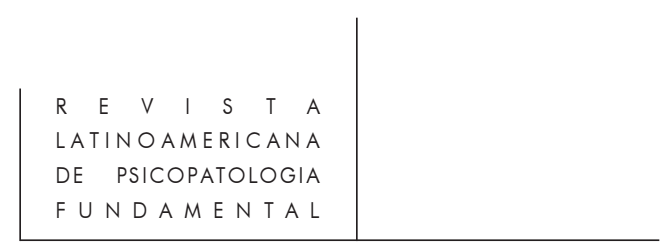

A segunda vertente de possibilidade se remete à noção de identificação como o processo pelo qual algo se faz semelhante: é o "como se". Aqui parece haver maior conforto para as reflexões: ao repetir a palavra do outro, a criança funciona "como se", se faz à semelhança de um sujeito que se movimenta simbolicamente, assumindo perspectivas discursivas.

No psiquismo, frente à dispersão anárquica pulsional, as relações identificatórias geram sistemas de organização. Não seria muito diferente pensar aqui a linguagem: a repetição da fala alheia, lugar de identificação, é forma de organizar um funcionamento simbólico caracterizado por absoluta dispersão. É o primado do impossível que, em cada ato de linguagem, é possibilitado parcial e temporariamente. E a repetição é, portanto, uma forma de "possibilizar". Parece, entretanto, que a repetição da fala alheia acaba por não "possibilizar", porque não traz a diferença (e, com ela, alguma possibilidade - de assumir alguma posição discursiva) impede o "fazer-se semelhante", a identificação, intensifica a dispersão de um tal modo que homogeneíza o funcionamento porque integralmente fragmentado. Instaura, assim, a estagnação. $O$ que seria repetir a fala alheia (colocar para dentro), destituí-la da possibilidade de sentido (desvitalizá-la), jogála para fora?

Ao outro fica destinado o silêncio porque paira o não-sentido. O outro, ele também deve fazer "como se" a criança fosse sujeito e confirmasse a alteridade. Aliás, é porque a mãe fala com a criança num "como se" que, certamente, ela vai falar (Rubino, 1989). Este ciclo é descrito também no psiquismo. Freire (1998) aponta: "O eu, para além de suas outras funções, forma-se ao dar lugar às primeiras identificações narcísicas e as mesmas se estruturam a princípio de forma incipiente através dessa ação psíquica que é feita de mão dupla: de um lado, os pais [...] ao imantar o bebê com cuidados e amor e, de outro, a própria criança - permeada pelo desejo do pai e da mãe - busca nos pais as primeiras relações identificatórias" (p. 96). É um "como se" de dupla mão. Mas, no ciclo infernal das repetições, o outro se cala e deixa de supor a criança sujeito. É como se fosse decretada a morte da palavra: para um que a destrói e cospe fora, um outro que se cala. E o que resta não é o silêncio constitutivo, aquele que habita as palavras, essência da polissemia. É, diferentemente, o mundo silenciado, calado, censurado. A repetição incessante decreta a morte da palavra. Assim, é preciso polemizar a repetição como lugar de identificação.

A palavra é uma invenção, quer dizer, pelo seu caráter polissêmico ela é sempre uma solução inédita para o conflito. Quando a criança repete as palavras do outro é como se ela as fizesse suas e, com isto, há diferença. A patologia mostra, ao contrário, que a criança não faz suas as palavras alheias e, nesta medida, elas deixam de ser uma invenção porque destituídas ficam da possibilidade de instaurar o novo, o diferente. Acaba a dialética condicional entre invenção/repetição, daí a "morte da palavra". 


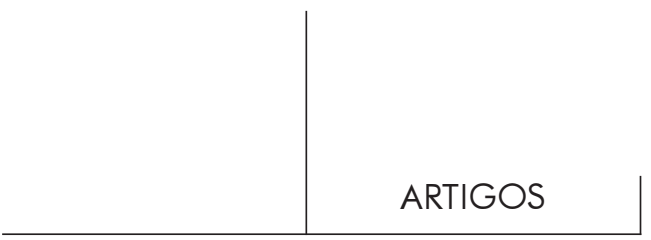

Se for para trabalhar com a metáfora de que ao repetir a criança põe a palavra na boca, tritura e cospe fora, talvez fosse possível evocar a idéia de incorporação que, segundo Laplanche e Pontalis (1992) apresenta três significações: obter prazer (pela penetração de um objeto), destruir esse objeto, assimilar para conservar dentro de si (p. 238). Como se vê, é possível estabelecer relação com as duas primeiras significações, mas parece que ao cuspir fora a criança nada conserva em si. Mesmo a incorporação (matriz da identificação) não pode ser evocada com plenitude. Não há possibilidade do "como se", dado que nada é conservado. Mas se não são possíveis as relações identificatórias, por que a repetição? Ou, se não é para falar, por que repetir o que o outro diz?

A idéia de identificação está referida ao inconsciente e, assim, é indicado acompanhar, nos casos de crianças com atraso de linguagem, as palavras de Atem (1998): "É o olhar (ou, investimento libidinal necessário) quando traduz a presença, que permite à criança receber/ouvir a voz da mãe [...]. Essa hipótese possibilita pensarmos que quando a relação especular não se instaura... também não é possível à criança ouvir sua mãe, o que significa não ouvir aquilo que as palavras dizem do lugar reservado a esta criança, do desejo que lhe é depositado" (p. 82). O investimento precisa ter mão dupla para haver alteridade: a criança fica surda para as palavras que, à margem das pulsões, desvestidas de sentido, viram "coisas" que rolam pelo espaço. Se o sujeito é efeito de identificações e elas se dão na alteridade, aqui a subjetividade não pode advir.

A lingüística oferece considerações que se dirigem para uma argumentação similar: o lugar discursivo designado à criança pela fala da mãe, determina de modo irreversível o funcionamento simbólico em que ela está inscrita. Pela fala do outro a criança assume uma posição na estrutura discursiva que, originariamente, é a terceira pessoa (ele). Por movimentos operados (pela especularidade, por exemplo) a criança assume outros lugares (do tu e do eu) denotando um processo geral que implica em identificação e alteridade, sem o que não há mudança. Aqui, de maneira semelhante, se a fala da mãe inscreve a criança na perspectiva da terceira pessoa e esse movimento se cristaliza, gerando uma estagnação na dialética necessária, a palavra também perde sua natureza polissêmica, estando impedida de possibilizar sentidos e, assim, gerar movimento. Se a significação está interditada (pela fala do outro), a palavra fica "muda". Entra e sai pela boca, à deriva. Entra e sai do corpo, sem parar e sem deixar rastro. Por que falar? A pergunta permanece, agora de uma outra forma: O que é esta palavra "muda" das repetições? Forrester (1983) discorrendo sobre a idéia de transferência, lembra a metáfora freudiana do "lugar certo" - "a cura depende de ele (o paciente) dispor suas palavras no 'lugar certo': em sons, sem permitir que elas fiquem enredadas no corpo" (p. 35). Colocar no som e não no corpo. À palavra é atribuída a condição de fazer a pulsão advir criação, solução para o 


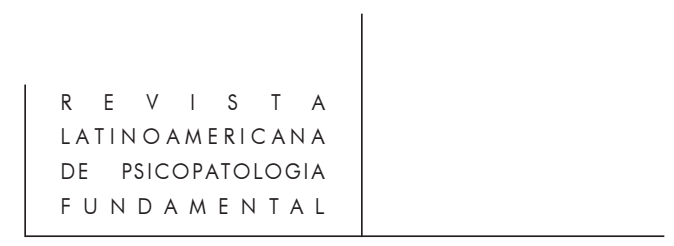

conflito. Mas e quando a palavra é muda e perpassa ininterruptamente o corpo? Será que o que há aí é o primado da errância pulsional? A palavra fica muda pelo absolutismo da polissemia?

\section{Bibliografia}

Aтем, L.M. (1998). "Autismo e defesa primária: questões sobre o sujeito e a transferência”, Revista Latinoamericana de Psicopatologia Fundamental, vol.1, no 1, março/98, São Paulo.

BerLinck, M.T. (1995). "Função e campo da transferência na psicanálise", Boletim de Novidades da Livraria Pulsional, ano VIII, no 72, abril/95, São Paulo.

(1998). "O que é Psicopatologia Fundamental?", Revista Latinoamericana de Psicopatologia fundamental, vol.1, no 1, março/98, São Paulo.

Bogochvol, A. (1997). "Algumas reflexões sobre a psiquiatria biológica", Boletim de Novidades da Livraria Pulsional, ano X, no 99, julho/97, São Paulo.

Figueiredo, L.C. (1997). "Subjetividade e psicanálise", Revista Psicanálise e Universidade, ㄲo 7.

Florence, J. (1994). "As identificações", in Identificações. Rio de Janeiro, RelumeDumará.

104 Forrester, J. (1983). A linguagem e as origens da psicanálise. Rio de Janeiro, Imago.

Freire, J.M.G. (1998). "Uma reflexão sobre a psicose na teoria freudiana", Revista Latinoamericana de Psicopatologia Fundamental, vol.1, no 1, março/98.

GARCIA-RozA, L.C. (1991). Introdução à metapsicologia freudiana - 1. Rio de Janeiro, Jorge Zahar.

Laplanche, J. e Pontalis, J.-B. (1992). Vocabulário da psicanálise. São Paulo, Martins Fontes.

Lemos, C.T.G. (1985). "On specularity as a constitutive process in dialogue and language acquisition", in Questions on Social Explanation: Piagetian Themes Reconsidered. Amsterdam, Holanda, John Benjamins.

ORLANDI, E. (1988). "Unidade e dispersão: uma questão do texto e do sujeito", Série Cadernos PUC, no 31, 1992. As formas do silêncio: no movimento dos sentidos. Campinas, Editora Unicamp.

Pereira de Castro, M.F. (no prelo). "A interpretação: a fala do outro e a heterogeneidade da fala da criança", in L.E.T.R.A.S., no 31 , UFSM, R.S.

Rubino, R. (1989). "Representando o interlocutor no período pré-lingüístico". Dissertação de Mestrado, PUC-SP. 


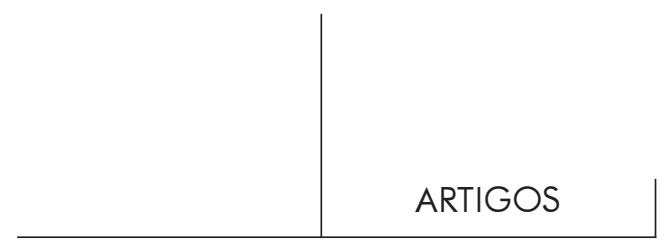

\section{Resumos}

Repetir la palabra ajena, al lado del silencio, es uno de los síntomas más frecuentes en las patologías del lenguaje. Tradicionalmente denominada ecolalia, esta repetición es entendida como producción no intencional, inconsciente, que no es representativa de conocimiento objetivo de la realidad. Es apenas un eco: un habla que para nada sirve.

Desde una perspectiva linguística más moderna, que toma la palabra como algo de la instancia discursiva, la repetición puede tener una outra interpretación. Del interior del concepto de enunciación sobreviene la idea del sujeto incompleto y del lenguaje incompleto, determinando para el lenguaje una génesis que nada más es, sino el brotamiento de un funcionamiento do tipo simbólico en que la repetición queda como un acontecimiento fundamental, necesario. Rescatada por esta linguística, la repetición permanece, exigiendo análisis. La patología del lenguaje muestra una repetición cuyo destino es diferente. Lejos de ser una ocurrencia fundamental, ella revela su perverso poder, ya que quita de la palabra su posibilidad de sobrevenir un decir.

La repetición, ocurrencia fundamental, pierde su carácter original y significa el patologico. Queda excesivo el lado conservador de las pulsiones, oscureciendo la heterogeneidad del sujeto, interrumpiendo cualquier anarquía en el funcionamiento pulsional, fuente de la diferencia necesaria. La palabra es una invención: por su carácter polisemico ella es siempre una solución inédita. Cuando los niños repiten la palabra de outro, es como si él la hiciese suya, estableciendo la diferencia. En la patología, de diferente modo, los niños hácen suya la palabra ajena $y$, asi, deja de ser una invención, porque queda distituida de la posivilidad de instaurar el nuevo. Acaba la dialectica condicional entre invención y repetición: surge la muerte de la palabra.

Répéter la parole d'autrui, à côté du silence, est un des plus frequents symptômes de la pathologie du langage. Pour tradition, la répétition, nommée écholalie, est entendue comme une production sans inténtion, inconscient, que ne représent pas un savoir objectif de la réalité. Elle est seulement un écho: comme une "bafouillage".

Sous la perspective d "une linguistique plus moderne, où la parole est comprise dans la notion de "énonciation" (que postule la polysémie de la parole et l'hétérogéneitée du sujet), la répétition peut recevoir une autre lecture. La notion de "enonciation" apporte l'idée d'un sujet toujours "incomplet" et d'un langage aussi "incomplet”. La genèse de la parole, dans ce cas, est exactement le début d'une activité symbolique dans laquelle la répétition reste un évènement trés important au cours du procès de constitution du sujet, en tant que est toujours répétition différenciel: implique un changement de la position de celui qui parle. La pathologie du langage dénonce, cependent, une autre chose: ici, la répétition n'est pas un 


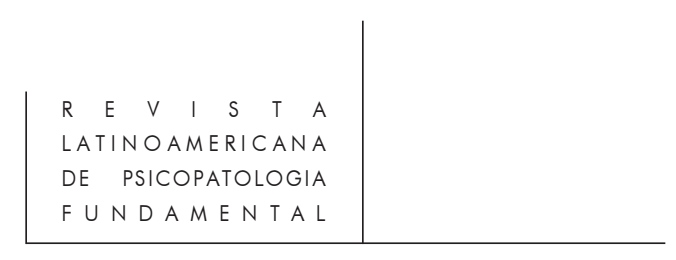

évènement important de la constitution du sujet parce que cet occurrence, à la vérité, devient l'interdiction de la possibilité d'une "enonciation". Sur ça, la Psychanalyse a, sûrement, beaucoup a dire.

La répétition n'est plus un important évènement du procès de constitution du sujet, dans ce contexte représent la pathologie. Le côté conservateur des pulsions est exorbité: l'hétérogéneitée du sujet reste effacée, parce que reste effacé, aussi, le côté anarchique des pulsions, exactement ce que fait la différence, ce qu'apporte la nouveauté nécessaire. La parole est une invention: pour sa polysémie, elle devient, toujours, une solution neuve. L'enfant répéte la parole d'autrui et cette parole devient leur parole et, ainsi, est faite la différence. Dans la pathologie ça ne se déroule pas. Donc, la parole ne devient pas une invention parce qu'elle n'apporte plus la nouveauté. C'est finie la dialetique entre l'invention et la répétition: la parole est morte.

The repetition of another person's word, with silence, is one of the most frequent symptoms in the language pathology. Traditionally named "echo", this repetition is understood as a non intentional production, unconscious, that is not representative of an objective knowledge of reality. It is only un echo: a useless speech.

Based on more modern linguistic perspective, which takes the word as something from the discoursive level (which bets on polissemy of the word and on the subject heterogeneity), repetition can have an other interpretation. From the concept of enunciation origins the idea of incompleteness of the subject and of the language, determining for language a genesis that is nothing else but sprouting of functioning of the symbolic type where repetition becomes a foundating event. Rescued by this linguistic, repetition remains, however, demanding analisys. The language pathology shows a repetition whose desting is different: far from noticing a founding occurence, it reveals its evil power, once it takes from the word its possibility to succeed a saying. Then, this event has another nature and about this, psychoanalisis has lots to say.

The repetition loses its original character and means the pathologic. The conservative side of instincts filling with smoke the heterogeneity of the subject, blocking any anarchy in the instinct functioning, source of the necessary difference. The word is an invention: because its polissemic character its always an new solution. When the child repeats the other person's word she/he is making her/his own, establishing the difference. In the pathology, on the other hand, the child doesn't make the other person's word her/his own word, this way, it is not an invention because the "new" doesn't exist anymore. The conditional dialetic between invention/ repetition ends causing the death of the word. 